\title{
MICROPROCESSOR CONTROLLED CAPACITOR BANK SWITCHING SYSTEM FOR SMART DISTRIBUTION NETWORKS
}

\author{
J. 0. Egwaile ${ }^{1, *}$ and F. 0. Osayamen ${ }^{2}$ \\ 1,2 Department of Electrical/Electronic EngineERING, University of BENIN, BENIN City, NiGERIA \\ Email addresses: ${ }^{1}$ joeranky@yahoo.com;2 pafestigal@yahoo.com
}

\begin{abstract}
In this work, analysis and development of a microprocessor controlled capacitor bank switching system for deployment in a smart distribution network was carried out. This system was implemented by the use of discreet components such as resistors, capacitors, transistor, diode, automatic voltage regulator, with the PIC16F876A microcontroller programmed in micro basic language serving as the main control centre. The microcontroller sends the relevant control signals to the relays to either switch on or switch off the banks when the voltage fall outside allowable limits. When the voltage returns to normal, it also switches off the capacitor banks to avoid overcompensating the lines. On test, the circuit was able to switch on the capacitor bank automatically when the voltage on the line drops below the preset value, thus helping to ensure that the voltage on the line stays within the acceptable value. It is strongly recommended that utility companies adopt this technology to address the problem of poor voltage profiles on the lines.
\end{abstract}

Keywords: voltage profile, capacitor bank, distribution network, microprocessor.

\section{INTRODUCTION}

The performance of a distribution system and quality of the service provided are not only measured in terms of frequency of interruption but in the maintenance of satisfactory voltage levels at the customers' premises. In this regard, utility companies in Nigera have been incapable of providing minimum acceptable international standard of electricity service over the past three decades. [13]. This is because the radial nature of distribution systems makes it impossible for all customers connected to a particular injection substation to enjoy the same voltage level. The voltage drop along the line increases with the line length, hence customers at the far end of the line experiences very low voltage far below the value stipulated by the regulatory authorities [7]. This could affect proper functioning of customer's equipment and can even reduce the service life of such equipment. Thus there is the need by service providers to put in place measures to control voltage in distribution systems. This is because most equipment and appliances operate satisfactorily over some 'reasonable' range of voltages
[8] hence, certain tolerances are allowable at the customer's end. It is common practice among utilities to stay within preferred voltage levels and ranges of variations for satisfactory operation of apparatus as set by various standards such as ANSI (American National Standard Institution). For example, power acceptability curves given by [6] indicate that steadystate voltage regulations should be within $+6 \%$ to- $12.5 \%$ for satisfactory operation of various electrical devices.

A growing recognition of the need to modernize the grid to meet these challenges has found articulation in the vision of a Smart Grid. This is because electrical energy has become so important that countries with insufficient power available for use are classified as underdeveloped countries [7].

Smart grid technology includes the application of automation and digital controls to power systems in general and to distribution systems in particular[13]. The primary purpose of voltage control in a smart distribution network is to maintain acceptable voltage at the service entrance of all customers served by the feeder under all possible operating 
conditions, and thus keep the voltage losses within acceptable limits.

\subsection{Causes of Losses/Voltage Drop in a Distribution System}

Loss minimization in distribution systems has assumed greater significance recently since the trend towards distribution automation will require the most efficient operating scenario for economic viability variations. Studies have indicated that as much as $13 \%$ of total power generated is wasted in the form of losses at the distribution level. [11].

There are many factors that influence the voltage at each customer service entrance, these include:

- The voltage on the transmission or sub transmission supply line. Under normal and abnormal situations, the supply line voltage fluctuates by a small amount. Voltage regulating devices must adjust the distribution primary voltage so that supply line voltage fluctuations do not cause the distribution primary voltage to drift out of the acceptable range.

- The feeder loading: During peak load conditions, the current (ampere) flowing on the feeder increases, and the voltage drop along the feeder due to the current flow increases. This results in decreased voltage for customers that are further from the substation end of the feeder. The voltage regulating devices must automatically raise the line voltage under peak load conditions to account for increased voltage drop. Conversely, when the feeder is lightly loaded, the voltage drop is lower, so the voltage regulating devices must lower the voltage to avoid possible high voltage conditions

\subsection{Causes of Power Loss in a Distribution System}

In distribution systems, effective voltage control methods can improve the systems voltage profile, reduce losses and improve the voltage regulation of the system. These methods include:

(a) Activating voltage regulating equipment at the substations bus such as Capacitors or LTCs.

(b) Balancing of loads on primary feeders.

(c) Increased size of feeder conductor.

(d) Transferring loads to new feeders.

(e) Installing new substations and primary feeders.

(f) Installing shunt capacitors or SVCs on primary feeders.

(g) Use of DFact devices. [4]
The most economical way of improving voltage profiles along a feeder, and is by using shunt capacitors.

The capacitor banks for voltage improvement are normally located at the same buses for both peak and off peak periods, there is need to automate the switching of the bank, to avoid injecting too much of reactive power, when they load on the network drops. This is part of the concepts that brings about the smartness of the grid, i.e. the ability of the grid to automatically adjust itself in order to ensure voltages at the consumer end stays within acceptable limits under all load conditions.

\section{CAPACITOR BANK SWITCHING SYSTEM}

The capacitor bank switching system developed in this work consists of several subunits as shown in the block diagram of figure 1.For simplicity, the line voltage being monitored is assumed to be $415 \mathrm{~V}$.

In the block diagram of Figure 1 the voltage monitor continuously samples the line voltage and produces an output which is proportional to the voltage on the $415 \mathrm{~V}$ line. This signal is fed to the control unit, which converts the signal from the voltage monitor to a digital signal via an inbuilt ADC. This digital signal is continuously compared with a reference voltage to determine which of the capacitor banks would be switch on to keep the voltage within acceptable limits. Again, as the line voltage increases, the control unit switches off the banks in turn to prevent the banks from overcompensating the lines. The section that follows outlines the design of each block of Figure 1

The capacitor banks in this design are programmed to switch on fifteen (15) seconds after sensing voltage outside acceptable limit, this can however be changed by simply adjusting the settings on the microprocessor programme.

\subsection{Design Analysis}

\subsubsection{Power supply unit}

The power supply unit was implemented using a 415/12V step down transformer $\left(\mathrm{TR}_{1}\right)$, an $1 \mathrm{C}$ bridge rectifier $\left(\mathrm{BR}_{1}\right)$, a $470 \mu \mathrm{F}$ filter capacitor and a $78051 \mathrm{C}$ $\left(U_{1}\right)$ voltage regulator as shown in Figure 2.

\subsubsection{The design of the voltage monitor circuit}

The Voltage monitor circuit continuously samples the line voltage and produces a DC output that varies with the line voltage as shown in Figure 3. For simplicity, the load is assumed to be balanced, so the 
sampled voltage is taken between any two of the three lines.

The circuit of Figure 3 consist of a step down transformer $\mathrm{TR}_{2}$, rated $450 / 15 \mathrm{~V}, 500 \mathrm{~mA}$, a bridge rectifier $\mathrm{BR}_{2}$. The filter circuit formed by the combination of $\mathrm{R}_{1}(10 \mathrm{k} \Omega)$ and $\mathrm{C}_{2}(470 \mu \mathrm{F})$ would output a near perfect DC signal as it would block any signal whose frequency is up to $1 \mathrm{HZ}$; (i.e. $\mathrm{f}_{\mathrm{c}}=\frac{1}{2 \pi R C}$ ) [2][10].

The output voltage of the rectifier and filter circuit serves as input to the voltage divider [5][1] network of resistor R1 and Rv1.

For a full wave bridge rectifier, average value of dc voltage is

$$
\mathrm{Vdc}=0.636(\mathrm{Vm}-2 \mathrm{VD})[9]
$$

Where $\mathrm{Vm}=$ peak value of transformer secondary voltage

$\mathrm{VD}=$ voltage drop across the diodes

Thus from Figure 3,

$$
V R v 1=\frac{V d c X R V 1}{R v 1+R 1}
$$

In (2), Vdc is the output voltage of the rectifier and filter circuit and VRv1 is the voltage drop across RV1, which serves as control input to the microcontroller. For a line voltage of $415 \mathrm{~V}, \mathrm{VRv} 1$ is adjusted by variable resistor Rv1 to read $10 \%$ of the input i.e. $4.15 \mathrm{~V}$.

Thus for VRv1 $=4.15 \mathrm{~V}, \mathrm{Vm}=15 \mathrm{~V}, \mathrm{VD}=0.7 \mathrm{~V}, \mathrm{Vdc}=$ $8.65 \mathrm{~V}, \mathrm{R} 1=10 \mathrm{k} \Omega, \mathrm{R}_{\mathrm{V} 1}$ is calculated from equation (1) to be $9.22 \mathrm{k} \Omega$. RV1 is implemented with a $10 \mathrm{~K} \Omega$ variable resistor adjusted to $9.22 \mathrm{~K} \Omega$.

The output of the voltage divider network which varies in accordance with the $415 \mathrm{~V}$ line voltage is used as signal to the analog input of PIC16F876A microcontroller unit.

\subsubsection{The design of the control unit}

The control unit continuously compares the input voltage from the voltage monitor circuit with a reference voltage and then sends a $5 \mathrm{~V}$ to the relevant relay to either switch on or switch off a capacitor bank depending on the voltage level. The circuit for the control unit is shown in Figure 4.

As shown in Figure 4, the circuit is implemented with a PIC16f876A microcontroller (MCU) which has a 10 bits inbuilt analog to digital converter (ADC) [12]. The signal from the voltage monitor is applied to the ADC input of the MCU.

The MCU is programmed to ensure that the switching of the capacitor banks is done to keep the output voltage within the range $94 \% \leq \mathrm{V} \leq 106 \%$ of the input voltage. The instruction set for the MCU is written in micro basic language.
Thus for a line voltage of $415 \mathrm{~V}$, the allowable output voltage range is between $390 \mathrm{~V}$ and $435.75 \mathrm{~V}$. At $415 \mathrm{~V}$, the potentiometer $\mathrm{R}_{\mathrm{v} 1}$ is adjusted till the output voltage of the monitor circuit is $4.15 \mathrm{~V}$. This means that the lower limit voltage will correspond to $3.90 \mathrm{~V}$, while the upper limit voltage will be $4.36 \mathrm{~V}$.

The inbuilt ADC of the MCU, is 10 bit wide [3], this gives a resolution of

$\mathrm{R}=1 / 2^{\mathrm{n}}$.

where $\mathrm{n}$ is the number of bits.

Thus resolution of the $\mathrm{ADC}=1 / 2^{10}=1 / 1024=$ 9.77X10-4.

This implies that at $5 \mathrm{~V}$ (minimum analog input voltage) the ADC output will be 1023 .

Therefore the lower limit voltage would be $1023 / 5 \mathrm{X}$ $3.9=797.94$

Similarly, the upper limit voltage would be $102315 \mathrm{X}$ $4.36=892$.

Thus the MCU is programmed to keep the ADC output between the binary equivalent of 797 and 892 .

The complete circuit diagram of the Capacitor bank switching system is shown in Figure 5.

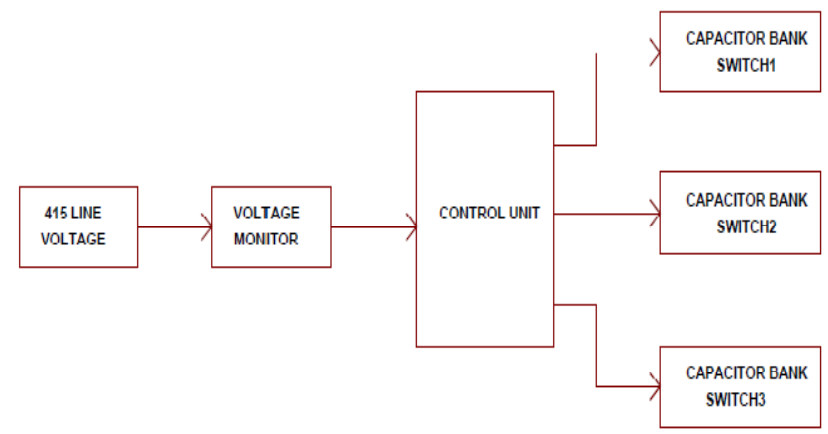

Figure 1: Block Diagram of Capacitor Bank Switching Circuit.

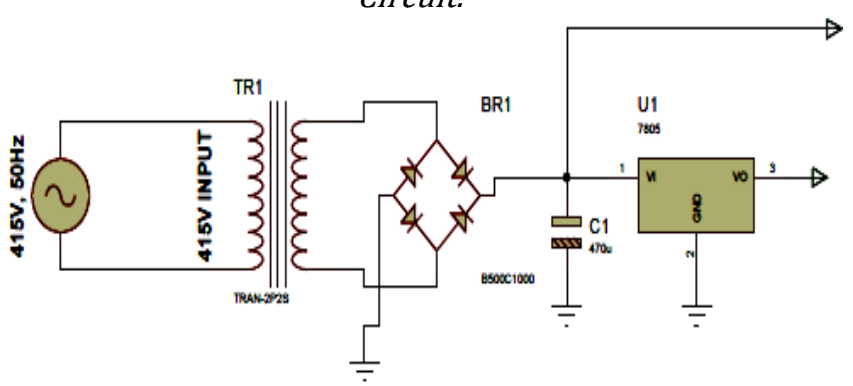

Figure 2: Power Supply Unit

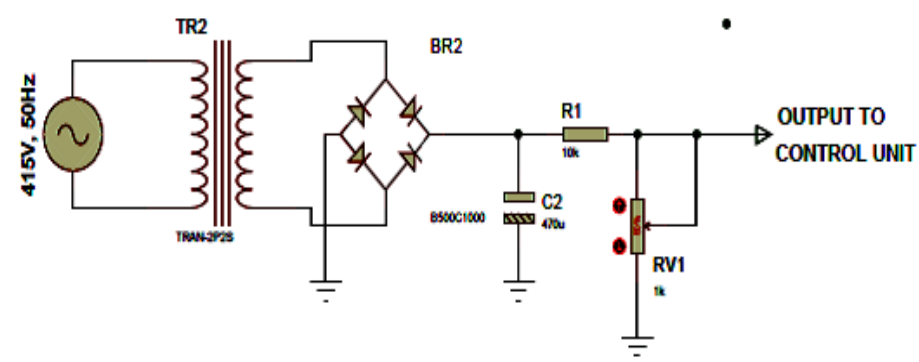

Figure 3: Voltage Monitor Circuit 


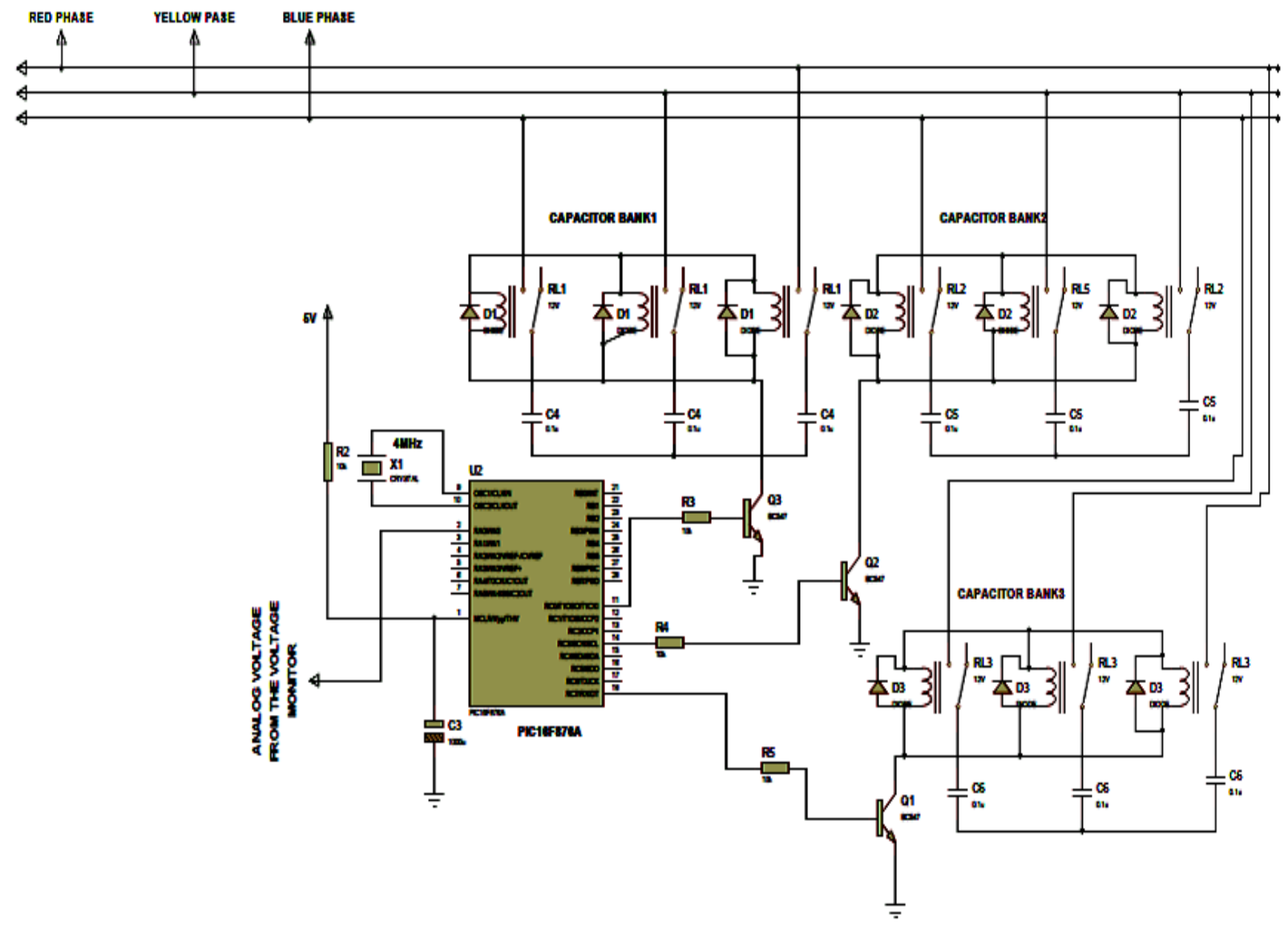

Figure 4: Capacitor Switching and Control Unit

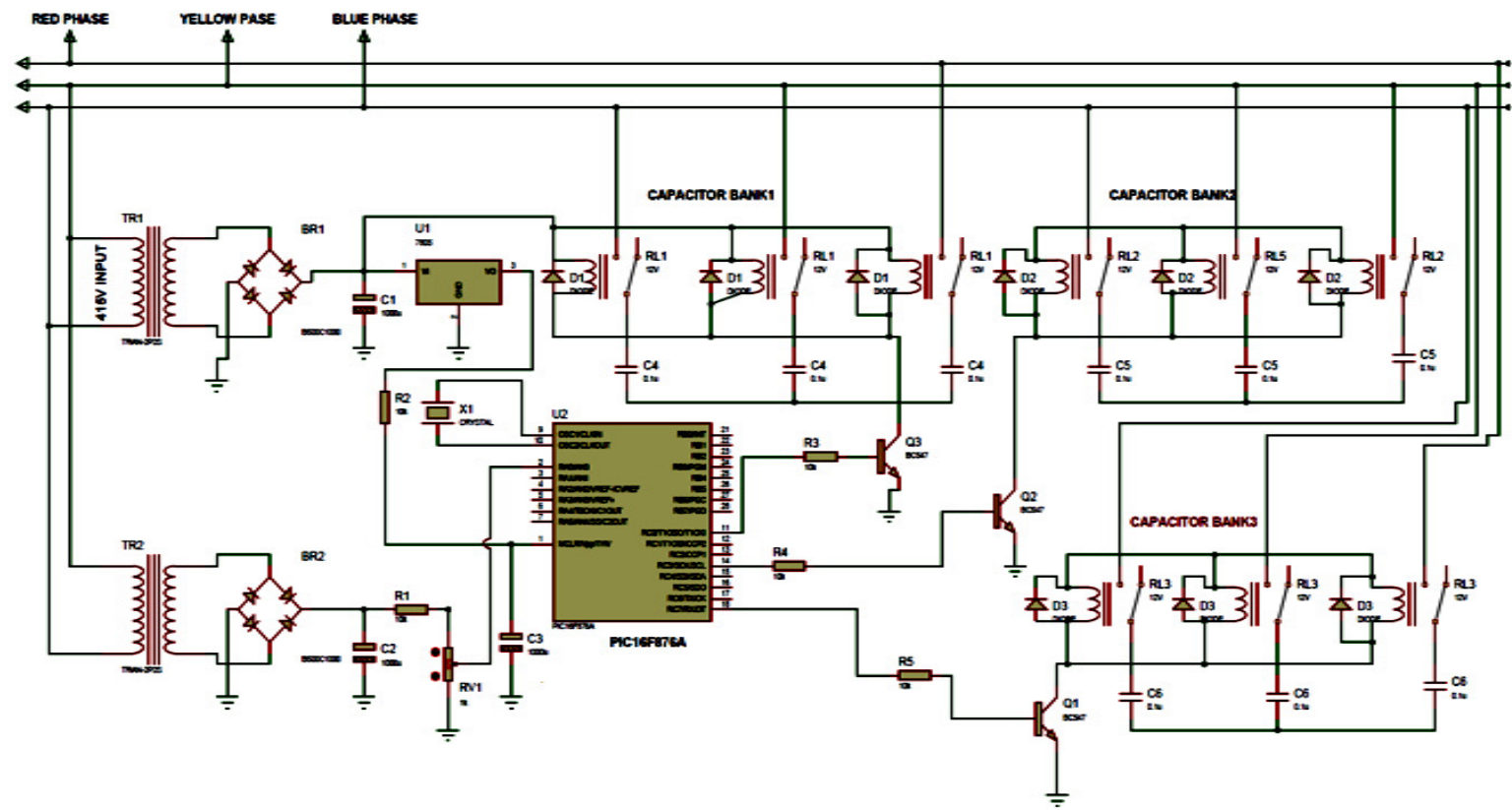

Figure 5: Diagram of Capacitor Switching Circuit.

\subsubsection{Principle of Operation of the Capacitor Bank Switching Circuit}

As shown in Figure 5, the Voltage monitor circuit which consist of a step down transformer $\mathrm{TR}_{2}$, rated $450 / 15 \mathrm{~V}, 500 \mathrm{~mA}$, a bridge rectifier $\mathrm{BR}_{2}$, and a filter circuit formed by the combination of $\mathrm{R}_{1}$ and $\mathrm{C}_{2}$ continuously samples the line voltage and produces a DC output that varies with the line voltage. The output voltage of the filter circuit is used as signal input to a voltage divider network of resistor $R_{1}$ and $\mathrm{R}_{\mathrm{V} 1}$. 
The output of the voltage divider network is used as the analog signal to the ADC input of the PIC16F876A microcontroller unit.

The PIC16F876A microcontroller (MCU) continuously compares the input voltage from the voltage monitor circuit with a reference voltage and then sends a $5 \mathrm{~V}$ to the relevant relay to either switch on or switch off a capacitor bank depending on the voltage level of the line.

The MCU is programmed to ensure that the switching of the capacitor banks is done to keep the output voltage within the range $94 \% \leq \mathrm{V} \leq$ $106 \%$ of the input voltage. The instruction set for the MCU is written in micro basic language. Thus for a line voltage of $415 \mathrm{~V}$, the allowable output voltage range is between $390 \mathrm{~V}$ and $435.75 \mathrm{~V}$.

\section{Table 1: Capacitor Switching Circuit Test Result.}

\begin{tabular}{|l|l|l|}
\hline S/N & INPUT VOLTAGE & STATUS OF CAPACITOR \\
\hline 1 & $\mathrm{~V} \geq 390 \mathrm{~V}$ & ALL BANKS SWITCHED OFF \\
\hline 2 & $375 \leq \mathrm{V} \leq 390$ & BANK 1 SWITCHED ON \\
\hline 3 & $360 \leq \mathrm{V} \leq 375$ & BANK1\&2SWITCHEDON \\
\hline 4 & $\mathrm{~V} \leq 360$ & BANK 1,2 \& 3 SWITCHED \\
\hline
\end{tabular}

\subsubsection{Experimental Test Result}

A prototype of the designed circuit was constructed and it worked satisfactorily on test. The test results are presented in Table 1, while the photo view of the prototype system constructed is presented in Figure 6.

\section{CONCLUSION}

The capacitor bank switching system developed is simple in construction, reliable and relatively cheap to construct. It would be very useful to utility providers as it will automatically switch "ON" or switch "OFF" the banks anytime the voltage on the line goes outside acceptable limits. One advantage of this is system is that it injects only the amount of reactive power required to compensate the lines, thus avoiding the consequence of overcompensating the lines.

It is recommended that utility companies should adopt this method of automatic line compensation, as this will mitigate voltage violations on the line and reduces losses associated with low voltage. Electric power consumers will ultimately benefit from this system as they will be able to consume power at acceptable voltages and payless for power consumed as losses would have been appreciably reduced.

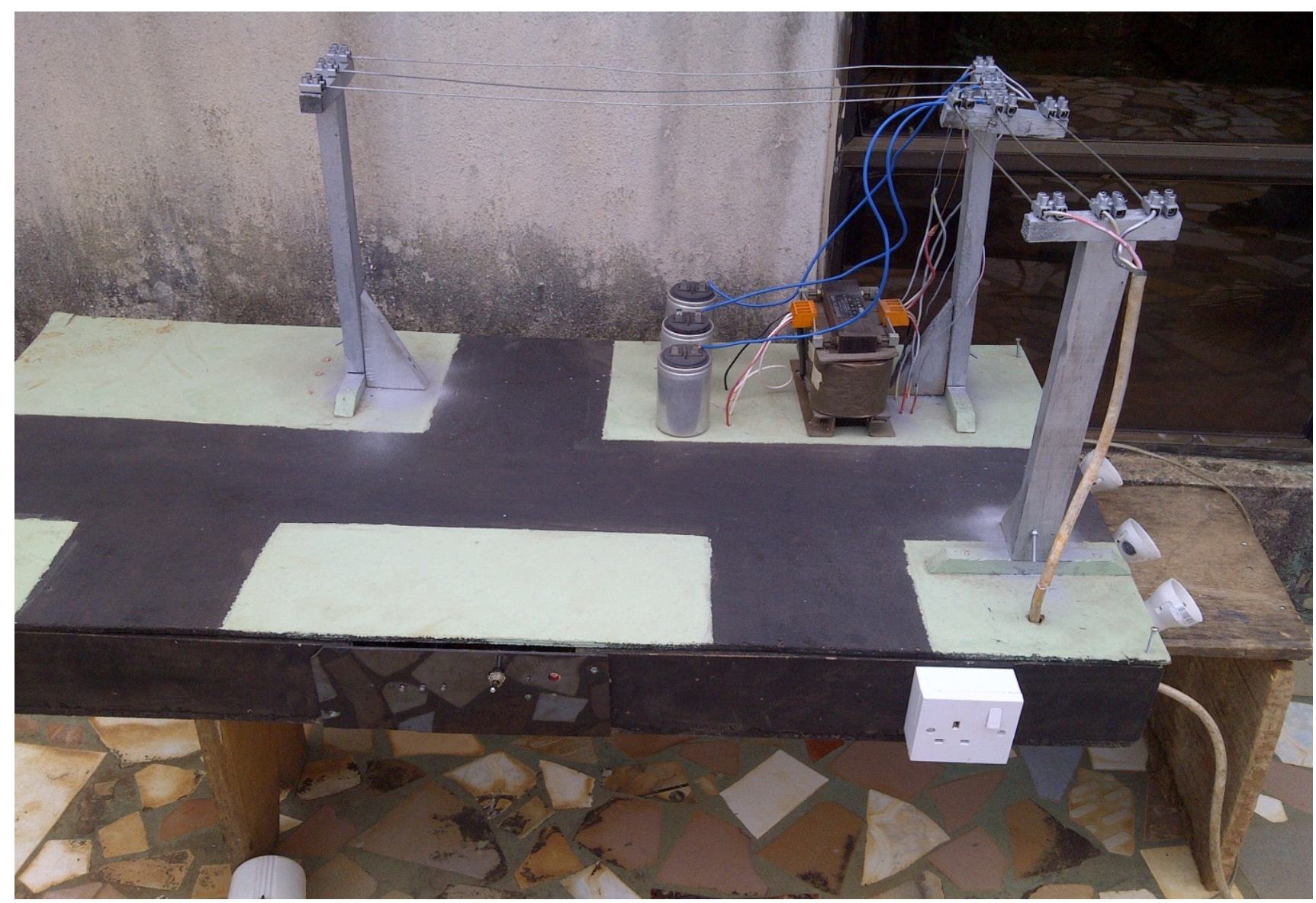

Figure 6: Photo View of the designed and constructed network 


\section{REFERENCES}

[1] Faissler W.L, 1991. "An Introduction to Modern Electronics", New Jersey: John Wiley \&Sons Inc.

[2] Floyd T.L. 1992 "Electronic Devices" New York: Macmillian Publishers.

[3] Gupta, A. 2013 "Microcontroller and Embedded Systems"New Delhi: S.K Kataria \& Sons Publishers

[4] Gupta, J.B (2009) " A Course in Power System'New Delhi: Sanjeev Kumar Kataria Publishers.

[5] Hesrick R.J, 2003 "DC/AC Circuits and Electronics: Principles and Applications". New York: Thomson Delmar Publishers. Pg 307

[6] IEEE orange book, IEEE standard 446

[7] Obe, E. S. And Onwuka, I. K. 2011, "Modelling and performance of self-excited two-phase reluctance generator", Nigerian Journal of Technology, Vol. 30, No. 2, pp. $55-66$.

[8] Onohaebi, S.O. Egwaile, J. Igimoh J. (2008) 'Use of Renewable Energy as Small off-Grid Applications to Enhance Electric Power Reliability in Nigeria. Journal of the Nigerian Institute of Production Engineers. Vol 9, No 1, pp 61 - 73.

[9] Onohaebi, S.O. Ike S.A. (2002) "Electrical Power Stability in Home -Development an Automatic
Voltage Stabilizer with Under and Over Voltage Protection. Journal of Electrical and Electronic Engineering, Vol. No 1, pp 56-66.

[10] Onohaebi, S.O. (2006) "Basic Electronics" Benin City: Mufti International Publishers,

[11] Schultz M.E., 2011 "Grob's Basic Electronics" $11^{\text {th }}$ Edition, New York: Mc Graw-Hill Publishers.

[12] Song, Y.H. Wang G.S; Johns A.T and Wang P.Y, (1997)"Distribution network reconfiguration for loss reduction using Fuzzy controlled evolutionary programming," IEE Trans. Generation., Transmission and. Distribution., Vol. 144.pp. 45-57.

[13] Ugwu, H. U. and Nwankwojike, B. N, Ogbonnaya O and Ekoi, E. J. 2012, "Energy and Economic losses due to constant power outages in Nigeria", Nigerian Journal of Technology, Vol. 31, No. 2, 181 $-188$.

[14] Verle, M. 2008. "PIC Microcontrollers" Belgrade Mikroelectronika; First Edition.

[13] Vijayapriya, P. Garauv, B. Kothari, D.(2010) "Smart Tariff for Smart Meters in Smart Grid. International Journal of Engineering and Technology, Vol 2 (5), pp 310-314. 